\title{
Intoxicação crônica por Amaranthus spinosus em bovino no semiárido paraibano
}

\author{
Chronic poisoning by Amaranthus spinosus in catlle in the semiarid region of Paraíba, Brazil
}

\author{
Diego Barreto de Melo ${ }^{\mathrm{I}}$ Sara Vilar Dantas Simões ${ }^{\mathrm{I}}$ Antônio Flávio Medeiros Dantas ${ }^{\mathrm{I}}$ \\ Glauco José Nogueira Galiza ${ }^{\mathrm{I}}$ Rodrigo Antônio Torres Matos $^{\mathrm{I}}$ \\ Rosane Maria Trindade Medeiros ${ }^{\mathrm{I}}$ Franklin Riet Correa $^{\mathrm{I}^{*}}$
}

\begin{abstract}
Descreve-se um caso de intoxicação por Amaranthus spinosus em bovino no estado da Paraíba, Brasil. Os principais sinais clínicos foram secreção nasal catarral, edema submandibular e de barbela e diarreia de odor fétido. Havia anemia, hipoproteinemia, hipoalbuminemia e concentrações séricas de ureia e creatinina aumentadas. Na necropsia, os rins estavam difusamente pálidos (superfícies natural e de corte) $e$ levemente aumentados de volume. Histologicamente, observouse nefrose tubular tóxica com acentuada regeneração epitelial tubular. O diagnóstico de intoxicação por A. spinosus deve ser incluído no diagnóstico diferencial da intoxicação por Combretum glaucocarpum (sin=Thiloa glaucocarpa) que, até o presente momento, era a única planta descrita como nefrotóxica na região Nordeste do Brasil.
\end{abstract}

Palavras-chave: plantas tóxicas, nefrose tóxica, Amaranthaceae, região semiárida do Brasil.

\section{ABSTRACT}

A case of poisoning by Amaranthus spinosus is reported in the state of Paraíba, northeastern Brazil. The main clinical signs were catarrhal nasal discharge, edema of the submandibular region and lower neck and diarrhea. There were anemia, hypoproteinemia, hypoalbuminemia, and increased serum concentrations of urea and creatinine. After a clinical manifestation period of 32 days the animal was euthanized in extremis. The kidneys were diffusely pale and slightly enlarged. Histologically, tubular toxic nephrosis with accentuated tubular regeneration was observed. The diagnosis of A. spinosus poisoning has to be included in the differential diagnosis of poisoning by Combretum glaucocarpum (sin=Thiloa glaucocarpa), which was previously the only plant causing nephrosis in cattle in the northeastern Brazilian region.

Key words: poisonous plants, toxic nephrosis, Amaranthaceae, Brazilian semiarid region.
As plantas do gênero Amaranthus, da família Amaranthaceae, são constituídas por aproximadamente 75 espécies, 60 delas originárias das Américas. São plantas invasoras de lavouras, desenvolvendo-se em terrenos férteis (FERREIRA et al., 1991). Não há informações na literatura sobre a distribuição geográfica das diferentes espécies de Amaranthus na região semiárida do nordeste Brasileiro, mas diversas espécies, conhecidas popularmente como bredo ou bredo de porco, são encontradas nessa região, principalmente como invasoras de lavouras e terrenos abandonados. A ingestão da planta pode ocasionar intoxicações caraterizadas por nefrose tubular tóxica.

No Brasil, em bovinos, foram descritos casos de nefrose tubular tóxica devido à ingestão de Amaranthus hybridus, Amaranthus blitum (FERREIRA et al., 1991) e Amaranthus spinosus (LEMOS et al., 1993) no Rio Grande do Sul. A intoxicação foi descrita em ovinos por A. spinosus no Rio de Janeiro (PEIXOTO et al., 2003) e em suínos por Amaranthus quitensis (SALLES et al., 1991) e Amaranthus viridis (KOMMERS et al., 1996) no Rio Grande do Sul. A planta é palatável para ruminantes e apresenta toxicidade durante a fase de frutificação. A dose tóxica é aparentemente alta, de 340 a $500 \mathrm{~g} \mathrm{~kg}^{-1}$ aproximadamente, mas a planta perde rapidamente a toxicidade após ser cortada (FERREIRA et al., 1991).

Os sinais clínicos da intoxicação são depressão, anorexia, emagrecimento, secreção nasal serossanguinolenta, hipomotilidade ruminal,

IHospital Veterinário, Universidade Federal de Campina Grande, (UFCG), 58700-000, Patos, PB, Brasil. Email: franklin.riet@pq.cnpq.br *Autor para correspondência. 
diarreia fétida e escura, edema submandibular, que pode atingir a região da barbela e posterior da coxa, polidipsia e decúbito prolongado. A morte ocorre de 3 a 10 dias após a observação dos primeiros sinais (FERREIRA et al., 1991; LEMOS et al., 1993). Os relatos no Brasil, além de serem todos descritos nas regiões Sul e Sudeste, se referem a casos de intoxicação subaguda, não havendo registro de aspectos epidemiológicos, clínicos e patológicos de casos de intoxicação crônica. O objetivo deste trabalho é relatar um caso de intoxicação crônica por A. spinosus em bovino no estado da Paraíba.

Os dados foram obtidos durante atendimento clínico de um bovino, fêmea, mestiça de Holandês, com quatro anos de idade, encaminhado ao Hospital Veterinário (HV) da Universidade Federal de Campina Grande, Campus de Patos. Realizou-se exame físico e coleta de amostras de sangue e urina para análises laboratoriais. Para complementação dos dados epidemiológicos, foi realizada visita à propriedade de origem.

$\mathrm{Na}$ anamnese, o proprietário informou que há quinze dias o animal apresentava aumento de volume submandibular e diarreia. Ao exame físico, foi observado escore corporal de grau 2, apatia, hiporexia, aumento dos linfonodos parotídeos e cervicais superficiais, edema submandibular e de barbela (Figura 1A), secreção nasal catarral, hipofonese cardíaca, ingurgitamento da jugular e diarreia de odor fétido.

Os exames laboratoriais revelaram: hematócrito 23\% [valor de referência (VR): 24-26\% (RADOSTITS et al., 2007)]; proteína total 4,9g dl-1 (VR: 5,7 a 8,1 $\mathrm{g} \mathrm{dl}^{-1}$ ); albumina $0,74 \mathrm{~g} \mathrm{dl}^{-1}$ (VR: 2,1 a 3,6g dl-1); ureia $86 \mathrm{mg} / \mathrm{dl}$ (VR: 42,8 a 64,2mg dl-1) e creatinina 2,3mg dl-1 (VR: 1,0 a 2,0mg dl-1). Em quatro exames realizados posteriormente, observou-se que os níveis de ureia permaneceram altos e os níveis de creatinina foram normalizados. Na urinálise, observou-se urina ligeiramente turva, proteinúria, presença de sangue oculto, células epiteliais escamosas, células epiteliais tubulares, cilindros celulares e cilindros leucocitários.

$\mathrm{Na}$ visita à propriedade, localizada no Município de Matureia, Paraíba, verificou-se que os quatro bovinos do rebanho tinham acesso a uma área de pasto nativo invadido por A. spinosus (Figura 1B e C) e havia um piquete de aproximadamente $50 \mathrm{~m}^{2}$ composto na quase totalidade pela planta, em estado de frutificação, que era utilizado como reserva de forragem. Os animais tinham acesso em forma intermitente ao piquete invadido pela planta, mas o proprietário não soube informar o tempo de permanência dos animais no local.

$\mathrm{O}$ animal permaneceu 17 dias no $\mathrm{HV}$, totalizando 32 dias de evolução clínica e, devido ao agravamento do quadro clínico, foi eutanasiado e necropsiado. Fragmentos de órgãos foram coletados e processados rotineiramente para exame histopatológico e corados por Hematoxilina e Eosina (HE). Fragmentos dos rins foram selecionados e corados pelo Tricômico de Masson e pelo Ácido Periódico de Schiff (PAS). Macroscopicamente observou-se edema do tecido subcutâneo na região ventral da barbela. $\mathrm{Na}$ cavidade torácica, havia aproximadamente 23 litros de líquido translúcido (hidrotórax), sendo também observado ascite e hidropericárdio. Havia também edema na região perirrenal, na parede do abomaso e no mesentério. Os rins estavam difusamente pálidos, levemente aumentados de volume (Figura 1D) e, ao corte, apresentavam palidez da superfície cortical e medular. Histologicamente, observou-se degeneração e necrose das células epiteliais tubulares (Figura 1E), afetando principalmente os túbulos proximais da região cortical, associada à intensa regeneração tubular, fibrose e infiltrado inflamatório mononuclear intersticial. Havia acentuada dilatação dos túbulos contorcidos proximais, principalmente na região cortical externa, muitos dos quais estavam desprovidos de células epiteliais de revestimento. Outros túbulos apresentavamse parcialmente recobertos por células com discreto citoplasma eosinofílico, de núcleos hipercromáticos, alongados ou arredondados, característicos de regeneração de células epiteliais tubulares. Em algumas áreas, havia aglomerados de células epiteliais em regeneração. Na luz de alguns túbulos, observaram-se discretos cilindros granulosos e hialinos, além de gotas hialinas, principalmente na região cortical interna e córtico-medular. Havia ainda proliferação de tecido conjuntivo fibroso intersticial, ocasionalmente associada à discreto infiltrado inflamatório mononuclear. A membrana basal tubular estava preservada (Figura 1F).

Após o exame físico e identificação dos sinais de edema submandibular e de barbela, hipofonese cardíaca (justificada posteriormente pela presença de líquido no tórax e pericárdio) e o ingurgitamento da jugular, suspeitou-se, inicialmente, de insuficiência cardíaca congestiva decorrente de pericardite traumática, enfermidade frequente na região. Porém a ausência de alterações na frequência cardíaca e os resultados laboratoriais de hipoproteinemia, hipoalbuminemia, proteinúria e elevação dos níveis de ureia e creatinina direcionaram o diagnóstico para insuficiência renal. Os cilindros granulosos observados na sedimentoscopia são característicos de degeneração tubular. A presença de A. spinosus na propriedade e os indícios de consumo da planta reforçaram o diagnóstico de insuficiência 

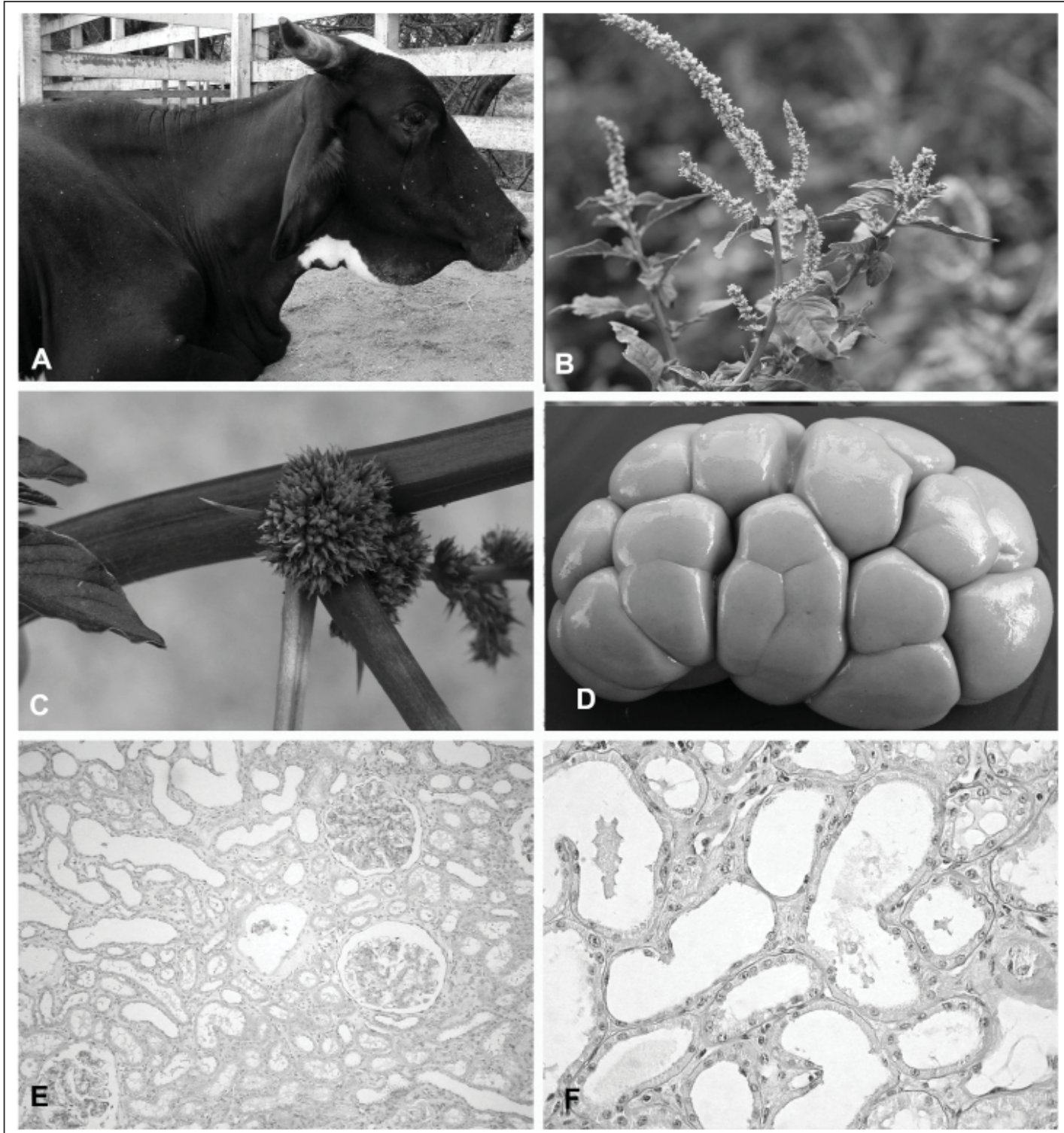

Figura 1 - A) Animal intoxicado por A. spinosus, em decúbito e com edema submandibular. B e C) A. spinosus em fase de frutificação. Município de Matureia, Paraíba. D) Rim de bovino intoxicado por A. spinosus com superfície subcapsular difusamente pálida e aumentado de volume. E) Túbulos contorcidos proximais desprovidos de células, apresentando moderada dilatação da luz, além de regeneração de células epiteliais e fibrose intersticial. HE. Obj. 20x. F) Túbulos contorcidos proximais em acentuado estágio de regeneração de células epiteliais e preservação da membrana basal tubular. PAS. Obj. 40x.

renal, que foi confirmado pela necropsia e achados histológicos de nefrose tubular.

A distribuição das lesões, observadas principalmente nos túbulos proximais da região cortical, ocorre pela maior susceptibilidade deste segmento à lesões tóxicas, devido ao seu elevado metabolismo celular e a sua exposição aos agentes tóxicos durante a reabsorção do ultrafiltrado glomerular. Pelo menos $60 \%$ da reabsorção do filtrado glomerular ocorre nos túbulos contorcidos proximais (VERLANDER, 2007). A regeneração tubular observada ocorreu por que a membrana basal permaneceu íntegra, atuando como base sobre a qual as células epiteliais em regeneração podem deslizar (NEWMAN et al., 2009). O curso clínico crônico da doença favoreceu a regeneração tubular. Em descrições anteriores da intoxicação por Amaranthus spp. em bovinos no Brasil (FERREIRA et al., 1991; 
LEMOS et al., 1993), o curso clínico variou de 3 a 10 dias, enquanto que, neste caso, a evolução foi de 32 dias. A regeneração observada provavelmente contribuiu para a normalização dos níveis séricos de creatinina, importante indicador de função renal.

Na região nordeste, o principal diagnóstico diferencial da intoxicação por Amaranthus spp. é a intoxicação por Combretum glaucocarpum (sin=Thiloa glaucocarpa), única planta da região descrita anteriormente como nefrotóxica (TOKARNIA et al., 1981). O principal fator a ser considerado para diferenciar as duas doenças é a presença de Amaranthus spp. e o fato de que a intoxicação por $\boldsymbol{C}$. glaucocarpum ocorre, exclusivamente, 10-25 dias após as primeiras chuvas. Outras doenças que devem ser consideradas no diagnóstico diferencial, que produzem diarreia crônica e que já foram diagnosticadas na região Nordeste, são a paratuberculose (MOTA et al., 2009) e a carência de cobre (RIET-CORREA, 2004).

Conclui-se que a intoxicação por $\boldsymbol{A}$. spinosus ocorre em bovinos no semiárido paraibano e que a enfermidade pode ter uma evolução crônica com significativa regeneração tubular.

\section{AGRADECIMENTOS}

Este trabalho foi financiado pelo Instituto Nacional de Ciência e Tecnologia (INCT) Para o Controle das Intoxicações por Plantas, Processo Conselho Nacional de Desenvolvimento Científico e Tecnológico (CNPq) 573534/2008-0.

\section{REFERÊNCIAS}

FERREIRA J.L.M. et al. Intoxicação por Amaranthus spp. (Amaranthaceae) em bovinos no Rio Grande do Sul. Pesquisa Veterinária Brasileira, v.11, p.49-54, 1991.
KOMMERS, G. D. et al. Intoxicação experimental por Amaranthus spp. (Amaranthaceae) em suínos no Rio Grande do Sul. Pesquisa Veterinária Brasileira, v.16, p.121-125, 1996.

LEMOS R.A. et al. Intoxicação espontânea por Amaranthus spinosus (Amaranthaceae) em bovinos. Pesquisa Veterinária Brasileira, v.13, p.25-34, 1993.

MOTA P.M.P.C. et al. Paratuberculosis in a dairy Gyr herd in the State of Paraíba, Brazil. Pesquisa Veterinária Brasileira, v.29, n.9, p.703-706, 2009. Disponível em: <http://www.pvb.com.br/ pdf_artigos/23-10-2009_00-06Vet641.pdf>. Acesso em: 26 out. 2013. doi. 10.1590/S0100-736X2009000900004.

NEWMAN, J.S. et al. Sistema urinário. In: McGAVIN, M.D.; ZACHARY, J.F. (Eds.). Bases da patologia em veterinária, 4.ed. Rio de Janeiro: Elsevier, 2009. p.613-691.

PEIXOTO, P.V. et al. Intoxicação natural por Amaranthus spinosus (Amaranthaceae) em ovinos no Sudeste do Brasil. Pesquisa Veterinária Brasileira, v.23, p.179-184, 2003. Disponível em: <http://www.scielo.br/scielo.php?script=sci_pdf\&pid=S0100736X2003000400007\&lng=pt\&nrm=iso\&tlng=pt $>$. Acesso em: 16 nov. 2012. doi: 10.1590/S0100-736X2003000400007.

RADOSTITS, O.M. et al. Reference Laboratory Values. In: Veterinary Medicine, $10^{\text {th }}$. ed. Philadelphia: Saunders Elsevier, 2007. p. 2047-2050.

RIET-CORREA, F. Suplementação mineral em pequenos ruminantes no semi-árido. Ciência veterinária nos Trópicos, v.7, n.2/3, p.112-130, 2004.

SALLES, M.S. et al. Perirenal edema associated with Amaranthus spp. poisoning in Brazilian swine. Veterinary and Human Toxicology, v.33, p.616-617, 1991.

TOKARNIA, C.H. et al. Intoxicação de bovinos por Thiloa glaucocarpa (Combretaceae) no Nordeste do Brasil. Pesquisa Veterinária Brasileira, v.1, p.111-132, 1981.

VERLANDER, W.J. Solute reabsorption. In: CUNNINGHAM, G.J.; KLEIN, B.G. Textbook of veterinary physiology, 4.ed. China: Elsevier, 2007. p.537-447. 